\title{
Incorporation of Multiwalled Carbon Nanotubes into High Temperature Resin Using Dry Mixing Techniques
}

\author{
Sayata Ghose ${ }^{\dagger}$ Kent A. Watson $¥$ Donavon M. Delozier ${ }^{\dagger}$ Dennis C. Working*, \\ Emilie J. Siochi*, John W. Connell§* \\ † National Research Council Research Associate located at NASA LaRC, \\ Hampton, VA 23681 \\ ¥ National Institute of Aerospace, 144 Research Drive, Hampton, VA 23666 \\ *NASA Langley Research Center, Hampton, VA 23681
}

\begin{abstract}
As part of an ongoing effort to develop multifunctional advanced composites, blends of PETI-330 and multi-walled carbon nanotubes (MWNTs) were prepared and characterized. Dry mixing techniques were employed and the maximum loading level of the MWNT chosen was based primarily on its effect on melt viscosity. The PETI-330/MWNT mixtures were prepared at concentrations ranging from 3 to $25 \mathrm{wt} \%$. The resulting powders were characterized for homogeneity, thermal and rheological properties and extrudability as continuous fibers. Based on the characterization results, samples containing 10, 15 and 20 wt \% MWNTs were chosen for more comprehensive evaluation. Samples were also prepared using in situ polymerization and solution mixing techniques and their properties were compared with the ball-mill prepared samples. The preparation and characterization of PETI-330/MWNT nanocomposites are discussed herein.
\end{abstract}

Keywords: carbon nanocomposite, polyimides, PETI-330, ball mill

$\S$ To whom correspondence should be addressed: john.w.connell@nasa.gov 


\section{INTRODUCTION}

Thermally stable, high-performance resins are required for use in composite structures on aerospace vehicles such as supersonic aircraft and reusable launch vehicles. Due to an excellent combination of physical and mechanical properties, aromatic polyimides have emerged as leading candidates for these applications [1, 2]. However, polyimides are difficult to fabricate into composites and in an attempt to improve their processability, controlled molecular weight imide oligomers containing phenylethynyl groups have been developed. These phenylethynyl groups are thermally unreactive up to $300{ }^{\circ} \mathrm{C}$ but react rapidly at temperatures of $350-371{ }^{\circ} \mathrm{C}$ without volatile evolution to yield high molecular weight polyimides. [3 14]. The combination of a large processing window and the formation of a product exhibiting good toughness, good microcrack resistance and excellent thermo-oxidative stability makes phenylethynyl terminated imide (PETI) technology very attractive for use in high performance composite and adhesive applications

PETI-330 is a low molecular weight imide oligomer that has a low and stable melt viscosity and a glass transition temperature of $330{ }^{\circ} \mathrm{C}$ after curing at $371{ }^{\circ} \mathrm{C}$. PETI-330 has been used for making composites by resin transfer molding (RTM), vacuum-assisted RTM (VARTM) and resin infusion (RI). PETI-330 laminates exhibit excellent properties [9, 10].

Material needs on some advanced aerospace vehicles such as Gossamer spacecraft require multifunctional capabilities. For example, the incorporation of carbon nanotubes (CNTs) into aromatic polyimide films provides sufficient electrical conductivity to dissipate electrostatic charge (ESC) build up without degrading mechanical properties or flexibility or significantly compromising the optical properties[15]. When the CNTs are thoroughly dispersed in the polymeric material, an interconnecting structure of CNTs is formed which provides a conductive pathway for charge to flow. 
Various methods have been attempted for achieving good dispersion of CNTs in the polymer. They include the preparation of the polymer in the presence of CNTs under sonication [16] and the use of alkoxysilane terminated amide acid oligomer to disperse the CNTs [17]. In applications where only surface conductivity is required, single-walled carbon nanotubes (SWNTs) were spray-coated on the surface of the polymer substrates [15]. In all these experiments, the concentration of CNTs was minimized in order to retain the optical properties of the films.

Unlike thin films needed for Gossamer spacecraft, structural components do not require optical transparency or low color. Thus the incorporation of multi-walled nanotubes (MWNTs), which are less expensive and have lower aspect ratio compared to SWNTs, was investigated for structural and electrical applications. The goal of this research was to achieve a sufficient concentration of MWNTs to improve electrical conductivity and modulus without severely reducing the melt flow properties (i.e. processability) of the matrix resin and to use a dry mixing technique for incorporating the MWNTs. Maintaining melt flow properties is important because melt processing is generally the preferred method of fabricating composites. However the process has not been extensively used for nanocomposites due to the fact that CNTs tend to form agglomerates under these conditions and are "filtered" by the reinforcing media. Usually, this can be minimized by the appropriate application of shear during mixing. For example, polymethylmethacrylate (PMMA) containing SWNTs has been produced using a combined method of solvent casting and melt mixing [18]. In this method small pieces of cast films were pressed between heated plates and the resulting film was again broken many times. The entire method was repeated several times and the film obtained by this method had a more homogeneous distribution of nanotubes and better mechanical properties than the original film. A miniature mixer molder has also been used to produce small quantities of well-dispersed mixtures of MWNT in PMMA [19]. 
The mixtures were then compressed into thin films and investigations of their dynamic mechanical behavior showed an increase in storage modulus.

Another recent method to disperse MWNTs is the use of a micro-scale twin-screw extruder. This device has been used for the melt mixing of MWNTs with polycarbonates [20] and polystyrene [21]. The high shear mixing necessary to disentangle and uniformly disperse the MWNTs in the matrix can be achieved with the extruder. The process of extruding the nanocomposite through a suitable die and subsequent drawing leads to continuous ribbons of nanocomposites that can be further processed into laminates. Alignment of nanotubes by drawing from the polymer melt resulted in significant improvements in elastic modulus and yield strength when compared to randomly oriented nanocomposites [21]. Morphological studies using transmission electron microscopy (TEM) and scanning electron microscopy (SEM) have shown interconnecting structures formed by the nanotubes that efficiently helps in load transfer between the polymer matrix and nanotube reinforcement [20,21]. SWNTs have been incorporated (up to $1 \%$ by weight) into Ultem ${ }^{\mathrm{TM}} 1000$, a thermoplastic polyetherimide, and melt processed to yield fibers [22]. Although the melt process was not optimized to fully disperse and align the SWNTs some improvements in mechanical properties were achieved. Typically melt processing works better for thermoplastics than thermosets due to melt stability in the required processing window. Oligomers endcapped with phenylethynyl groups possess the right combination of low melt viscosities and excellent melt stability at $250-280^{\circ} \mathrm{C}$ suitable for melt processes like injection molding or extrusion.

Ball-milling is a mechanical process that leads to local generation of high pressure as a result of the collision between the grinding media [23]. The method has been used to obtain nano-barrels from cup-stacked carbon nanotubes [24], transform nanotubes to nanoparticles (ellipsoidal and spherical) [25], generate nanostructures from graphite [26 - 27] and shorten the lengths of nanotubes [28 - 29]. Polyethylene terephthalate (PET) was 
compounded with various grades (5 wt \%) of carbon nanofibers (CNF) by ball milling [30] followed by extrusion or melt mixing but to date there is no reported work on dry compounding of polymers with MWNTs using the ball mill.

The fabrication of nanocomposites that contain high loadings ( $>3 \%$ by weight) of carbon nanotubes has been elusive. The objective of this research was to combine PETI-330 with high loadings of MWNTs using a dry mixing technique like ball-milling prior to fabricating nanocomposites by injection molding. Preparation of samples containing various loading levels of MWNTs followed by their characterization are presented in this paper. Based on the properties, select samples were chosen for injection molding. For the purpose of comparison, samples were prepared using solution techniques i.e. by solvent mixing and in situ preparation of PETI-330 and MWNTs.

\section{EXPERIMENTAL}

\section{Materials}

2,3,3',4'-Biphenyltetracarboxylic dianhydride (a-BPDA) was obtained from Ube Industries, LTD. and recrystallized from a mixture of toluene and acetic anhydride to yield white crystals, $\mathrm{mp}$ 196.5-198 ${ }^{\circ} \mathrm{C}$. 1,3-bis(4aminophenoxy)benzene (1,3,4-APB) was obtained from Chriskev, Inc. and used as received (mp 114-115 $\left.{ }^{\circ} \mathrm{C}\right)$. 1,3-Diaminobenzene (m-DAB) was obtained from Aldrich Chemical Co. and used as received (mp 65-66 ${ }^{\circ} \mathrm{C}$ ). 4phenylethynylphthalic anhydride (PEPA) was received from Daychem Laboratories, Inc. and used as received (mp 151-152 ${ }^{\circ} \mathrm{C}$ ). Anhydrous $N$ methyl-2-pyrrolidinone (99.8\%, NMP) was obtained from Aldrich and used asreceived. PETI-330 was obtained from JFC Technologies, Bound Brook, NJ and the MWNTs (35 - $50 \mathrm{~nm}$ diameter according to manufacturer) were procured from The University of Kentucky, Lexington, KY and used as received. 


\section{Preparation of PETI-330 with 10\% (wt/wt) MWNT: dry mixing}

Dry mixing of PETI-330 and MWNTs was carried out in alumina-fortified porcelain jars using cylindrically shaped zirconia grinding media $(9.5 \mathrm{~mm} \mathrm{x}$ $9.5 \mathrm{~mm}$ ). The jars were placed on rollers (120 rotations per min) and rotated

for $48 \mathrm{~h}$. Initially, the mixing was done on a small scale using jars with a capacity of $0.4 \mathrm{~L}$. Mixtures containing 3, 5, 7, 10, 12, 15, 20 and 25 wt \% MWNTs were prepared. Based on the melt rheology and other characterization, two samples were chosen for scale up that was performed using a $1.9 \mathrm{~L}$ jar. After $48 \mathrm{~h}$ of mixing, the grinding media was separated from the powder using a sieve and the powder was collected. Typical recovery yields ranged from $70-80 \%$ of the total weight due to the adherence of the powder to the walls of the jar and the grinding media.

\section{Preparation of PETI-330 with 10\% (wt/wt) MWNT: in situ method}

A phenylethynyl terminated imide oligomer was prepared at a calculated $M_{n}$ of $\sim 750 \mathrm{~g} / \mathrm{mol}$ (excluding the molecular weight of the end groups) in the presence of MWNT using the following procedure. A $100 \mathrm{~mL}$ three-neck round-bottom flask equipped with a mechanical stirrer, nitrogen inlet and condenser was charged with 1,3,4-APB (2.7291 g, $9.335 \times 10^{-3}$ mol), 1,3-DAB, (1.0095 g, $\left.9.335 \times 10^{-3} \mathrm{~mol}\right)$ and NMP (13.0 g). To this solution was added 1.10 g MWNT. Additional NMP (7.0 g) was added and the mixture was stirred at room temperature for $10 \mathrm{~min}$. a-BPDA (2.9216 $\left.\mathrm{g}, 9.930 \mathrm{x} 10^{-3} \mathrm{~mol}\right)$ and PEPA (4.3397 g, $\left.1.7482 \times 10^{-2} \mathrm{~mol}\right)$ were added followed by NMP (5.66 g) to make a $30 \%$ (wt/wt) mixture. The viscous black mixture was stirred at room temperature for $15 \mathrm{~min}$ and additional NMP (15 g) was added. The condenser was replaced with a Dean-Stark trap and toluene $(20 \mathrm{~mL})$ was added to the mixture. The reaction mixture was heated to $170{ }^{\circ} \mathrm{C}$ overnight. Water from cyclodehydration was removed by azeotropic distillation with toluene. The imide oligomer (PETI-330)/MWNT solid was isolated by distilling the toluene 
and pouring the reaction mixture into water to precipitate a dark grey solid. The PETI-330/MWNT solid was washed several times in hot water and then dried at $110{ }^{\circ} \mathrm{C}$ overnight. The mixture was then dried in a forced air oven at $150{ }^{\circ} \mathrm{C}$ for $4 \mathrm{~h}$. The yield was $\sim 95 \%$.

\section{Preparation of PETI-330 with 10\% (wt/wt) MWNT: solution method}

Into a $100 \mathrm{~mL}$ three necked round bottom flask equipped with a mechanical stirrer and nitrogen inlet were placed PETI-330 (11.00 g) and NMP (40 g). The mixture was heated to $120^{\circ} \mathrm{C}$ and stirred until all solids dissolved. MWNT (1.10 g) was added to the solution followed by additional NMP (10 g). The black mixture was stirred at $\sim 70{ }^{\circ} \mathrm{C}$ for $5 \mathrm{~h}$. The PETI-330/MWNT solid was isolated by pouring the reaction mixture into water to precipitate a dark grey solid. The PETI-330/MWNT solid was washed several times in hot water and dried at $110{ }^{\circ} \mathrm{C}$ overnight. The mixture was then dried in a forced air oven at $150{ }^{\circ} \mathrm{C}$ for $4 \mathrm{~h}$. The yield was $\sim 95 \%$.

\section{Other characterization}

Differential scanning calorimetry (DSC) was performed on the powder samples obtained from ball-milling using a Shimadzu DSC-50 thermal analyzer at a heating rate of $20{ }^{\circ} \mathrm{C} / \mathrm{min}$ with the $\mathrm{Tg}$ taken as the mid-point of inflection of the differential heat flow $(\Delta \mathrm{H})$ versus temperature curve. The samples were cured in a sealed aluminum pan at $371{ }^{\circ} \mathrm{C}$ for $1 \mathrm{~h}$, cooled to room temperature and then heated again to $450{ }^{\circ} \mathrm{C}$ to determine the $\mathrm{Tg}$. Thermogravimetric analyzer (TGA) measurements in air (flow rate - 50 $\mathrm{ml} / \mathrm{min}$ ) were performed on the powder samples using an Auto TGA $2950 \mathrm{HR}$ (TA Instruments, DE). The samples were heated at $20^{\circ} \mathrm{C} / \mathrm{min}$ to $100{ }^{\circ} \mathrm{C}$, held for 30 mins to drive off any moisture, and heated to $600{ }^{\circ} \mathrm{C}$ at a rate of 2.5 ${ }^{\circ} \mathrm{C} / \mathrm{min}$. Dynamic rheological measurements were obtained using an Advanced Rheometric Expansion System (ARES) Rheometer from 
Rheometrics, Inc. The measurements were carried out under nitrogen atmosphere in an oscillatory shear mode using parallel plate geometry (30 $\mathrm{mm}$ diameter) at a heating rate of $4{ }^{\circ} \mathrm{C} / \mathrm{min}$ from 100 to $371^{\circ} \mathrm{C}$. The top plate was oscillated at a variable strain and a fixed angular frequency of $100 \mathrm{rad} / \mathrm{s}$ while the lower plate was attached to a transducer that recorded the resultant torque. High-resolution SEM images were obtained using a Hitachi S-5200 field emission scanning electron microscope (FE-SEM) equipped with a "through-the-lens" secondary electron detector operating at or below $1 \mathrm{kV}$. The composite images were obtained in low voltage mode in order to set up a stable local electric field on the sample while minimizing beam-induced damage. Both the powder and the sample obtained from the ARES were scanned. High-resolution TEM was performed with a CM-200 HR-TEM (Philips). Powder samples were dissolved in NMP at $70^{\circ} \mathrm{C}$ and PELCO ${ }^{\circledR}$ Center-Marked Copper Grids, (150 mesh and $3.0 \mathrm{~mm}$ O.D.) were dipped in the solution and characterized by TEM. Neat nanotubes were sonicated in ethanol for 5 min before dipping the grids. Raman spectroscopy was carried out using a Thermo Nicolet Almega Dispersive Raman spectrometer equipped with a $785 \mathrm{~nm}$ laser. The pinhole was $100 \mu \mathrm{m}$ and the spectral range was $3434-72 \mathrm{~cm}^{-1}$. The powder samples were also extruded through a Laboratory Mixing Extruder (LME, Dynisco, MA). The temperature of the mandrel was set at $200-210{ }^{\circ} \mathrm{C}$ and the temperature of the die $(1 \mathrm{~mm}$ diameter) was set at $230{ }^{\circ} \mathrm{C}$. The axial gap size was set at $0.64 \mathrm{~mm}$ and the rotor speed was $270 \mathrm{rpm}$. Elemental analysis of the neat MWNTs was performed by Desert Analytics, (Tucson, AZ) by combustion with the aid of tungsten trioxide ( $\left.\mathrm{WO}_{3}\right)$.

\section{RESULTS AND DISCUSSION}

Melt viscosity of ball-milled PETI-330/ MWNT samples: 
The complex viscosity of the neat as well as MWNT-loaded PETI-330 samples was determined from the ARES. Discs of the samples were prepared by compression molding approximately $0.75 \mathrm{~g}$ of the sample at room temperature and subsequently inserted in the test chamber at $100{ }^{\circ} \mathrm{C}$. The specimens were heated to $280{ }^{\circ} \mathrm{C}$ at a rate of $4{ }^{\circ} \mathrm{C} / \mathrm{min}$ and held at $280{ }^{\circ} \mathrm{C}$ for $2 \mathrm{~h}$ to assess the melt stability. Heating was then continued at the same rate to $371{ }^{\circ} \mathrm{C}$ and held for $100 \mathrm{~s}$. Figure 1 shows the melt viscosity curves of the neat and MWNT loaded samples. It is important to note the melt viscosity of the samples at the steady temperature of $280{ }^{\circ} \mathrm{C}$ as the resin is injected at this temperature. The neat resin has a low melt viscosity, between 5 and 10 poise. At $280{ }^{\circ} \mathrm{C}$ and a fixed strain rate, the viscosity shows an increasing slope. The phenylethynyl groups do not readily react at this temperature so no significant curing of the resin is taking place. This has been tested in the DSC when no cured $\mathrm{Tg}$ was obtained on samples held at $280^{\circ} \mathrm{C}$ for $2 \mathrm{hrs}$. The only other plausible explanation is that some volatiles are being released. As anticipated, when heating is resumed after $2 \mathrm{~h}$, the viscosity shows a decrease with increase in temperature. When the temperature reaches $>300$ ${ }^{\circ} \mathrm{C}$, the phenylethynyl group starts to react and consequently the viscosity increases. For the MWNT filled samples, the melt viscosity is reasonably steady at $280{ }^{\circ} \mathrm{C}$ and increases with increase in the wt \% of MWNTs. An exception is in the case of $25 \mathrm{wt} \%$ MWNT filled PETI-330 where the melt viscosity drops to a value lower than that of the 15 and $20 \mathrm{wt} \%$ MWNT. The reason for this is not clear, but it is possible that at higher loadings the MWNTs are acting as a lubricant and thus preventing proper friction with the plates of the rheometer causing the viscosity to appear lower. It may also be that at higher loadings the dispersion is less uniform leading to agglomerates of MWNTs and the viscosity is effectively lower. The melt 
viscosity for 20 wt $\%$ MWNT is $\sim 28,000 \mathrm{P}$ which is lower than the tolerable value of $60,000 \mathrm{P}$ for injection molding thus making loadings up to $20 \mathrm{wt} \%$ a suitable composition for scale up.

\section{HRSEM images of ball-milled PETI-330/ MWNT samples:}

CNTs tend to form agglomerates which can be minimized by the appropriate application of high shear during mixing. Melt mixing of MWNTs with various thermoplastics like PMMA, polycarbonate, polypropylene and polyethylene have been successful and SEM images showing the uniform dispersion of the tubes have been obtained [31 - 32]. However, the only reported work on shear mixing of CNTs and polyimides involves mixing in a mechanical blender for a few minutes [33] and SEM pictures could be obtained only at the highest concentration of $14.3 \mathrm{wt} \%$ MWNTs. Typically all polymers are insulating and exposure to the electron beam would cause them to burn. In this work, HRSEM images could be obtained for both the powder samples and the samples from the ARES even at a loading level of $5 \mathrm{wt} \%$, an indication that there is a reasonably good dispersion of nanotubes in the polymer matrix to form a conductive network.

Figure 2 shows the HRSEM pictures of neat MWNTs as well as powder PETI-330/MWNT samples obtained after ball-milling. As evident from the Figures 2 (c) and (d), there is an abundance of MWNT bundles between polymer particles in the case of $25 \mathrm{wt} \%$ loading. At high magnifications ( 25 $\mathrm{k})$, the tubes do not appear to be damaged as a result of the ball milling (Figure $2(\mathrm{e})$ and (f)). However, it was not possible to obtain images of tips of the tubes at higher magnifications. The typical diameters of individual tubes vary from $30-40 \mathrm{~nm}$ according to the manufacturer but the diameters observed in this study are larger and usually $50-100 \mathrm{~nm}$. After ball milling, the diameters are in the range of $200 \mathrm{~nm}$ which might indicate the presence of polymer coating on the surface of the nanotubes. 
Figure 3 shows the images of the samples after testing in the rheometer. Figures 3 ( $a$ and $b$ ) indicate the dispersion of the MWNTs in the matrix. In Figure 3 (b), the tubes have a bright coating on them which is an indication of less conductive polymer coating on the nanotube surface. The places where the tubes enter the polymer matrix have a dark circle around them which arises due to a difference in conductivity of the tubes and the matrix. With the ARES samples it was possible to go to higher magnifications $(\sim 60 \mathrm{k})$ and it was observed that the tips of some of the tubes seem to be damaged. However, it is not certain whether the damage was a result of ball milling or a result of the shearing action of the rheometer followed by fracture of the disc.

\section{TEM of MWNTs and ball-milled samples:}

TEM images were obtained in order to get an idea about the effect of ball milling on the structure of the MWNTs. Figure 4 shows the images of the nanotubes as received from the University of Kentucky. Ethanol was added to the MWNTs and the suspension was sonicated for about 5 min after which the copper grid was dipped into the suspension to obtain a thin layer of tubes. It is apparent from Figure 4(a) that the outer walls of the tubes are not smooth but have irregularities that may have been generated during their synthesis. There is a hollow channel that runs through the middle of the tubes but it usually ends before the tip of the tube. Often there are some particles within these channels and Energy Dispersive Spectroscopy (EDS) (Figure 4 (c)) revealed that these are iron (Fe) particles (iron was used as the catalyst during the synthesis of the MWNTs). A higher magnification (scale: $5 \mathrm{~nm}$ ), as seen in Figure 4(b), reveals three distinct regions in the image. The first is the Fe core of the catalyst particle (dark region), the second is the interface region between the Fe particle and the carbon, and the third is the carbon encapsulation. There is a distinct change in the distance and direction of the lattice planes in the interface region. The walls of the tubes also show 
regions of contrast (Figure 4 (d)) and on magnification, kinks are found on the walls of the tubes that result in a change in the direction of the lattice planes forming a sieve-like structure. A similar structure with defects in the form of "cross-struts" perpendicular to the axis of the tube has been observed in other neat MWNTs [34].

The PETI-330/MWNT samples obtained after ball milling were dissolved in hot $\left(70^{\circ} \mathrm{C}\right) \mathrm{NMP}$ and a copper grid was dipped into the solution to prepare samples for TEM imaging. Figure 5(a) shows the image of the nanotubes with clumps of polymer sticking to them. The Fe catalyst present in the central channel is also observed in this figure. On closer examination of the walls, two distinct features are seen by their difference in contrast as singled out in Figure 5(b). At a higher magnification (scale: $10 \mathrm{~nm}$ ) distinct regions that appear like splits on the walls of the tube (Figure 5 (c)) are seen. Focusing on one split in Figure 5(d) (scale: $5 \mathrm{~nm}$ ) it is noticed that the direction of the lattice plane changes immediately following such a split leading to regions of contrast in the image at lower magnifications. Although regions of contrast and change in direction of lattice planes in the neat MWNTs were seen, the splits as seen in Figure 5 were not observed. The splits are possibly generated as a result of the ball milling although complete destruction of the tubes are not observed. Another significant observation from the TEM images of the neat MWNTs and the ball-milled samples was that the lengths of the tubes were reduced as a result of ball milling.

\section{Raman Spectroscopy:}

The Raman spectra of MWNTs typically exhibit two optically active phonon modes [35]. The first one is an optically active in-plane stretching E2g mode, the so-called graphite mode, popularly termed as the "G" band with a peak around $1580 \mathrm{~cm}^{-1}$. There is also another strong band around $1350 \mathrm{~cm}^{-1}$ referred to as the "D" band and is attributed to disordered graphitic 
structures. It should be remembered that during the manufacturing of CNTs disordered carbonaceous compounds including amorphous carbon are produced and these show up in the D-band. For the neat PETI-330, no peak is observed at $1000-2000 \mathrm{~cm}^{-1}$. In the case of PETI-330/MWNT samples, with lower concentrations of tubes (3\%), both the $\mathrm{G}$ and $\mathrm{D}$ bands are completely masked by the spectrum of the polymer. Bands are observed at concentrations of $5 \%$ or higher and the intensities of both the bands increase with increasing concentration of nanotubes.

\section{Other characterization:}

Elemental analysis of the MWNTs showed Fe content of $\sim 4$ wt $\%$ and a carbon content of $\sim 96 \mathrm{wt} \%$. The $\mathrm{Tg}$ of the neat polymer was $326{ }^{\circ} \mathrm{C}$ and only a small change in $\mathrm{Tg}$ was observed with the addition of nanotubes with the value reaching $332{ }^{\circ} \mathrm{C}$ when $20 \mathrm{wt} \%$ MWNTs were added (Table 1). The thermal degradation data from the TGA showed the temperature of $5 \mathrm{wt} \%$ loss decreased as the MWNT content increased. The neat resin lost $5 \mathrm{wt} \%$ at $508{ }^{\circ} \mathrm{C}$, the neat MWNT lost 5 wt $\%$ at $512{ }^{\circ} \mathrm{C}$ whereas the sample containing 25 wt $\%$ MWNT lost 5 wt $\%$ at $462{ }^{\circ} \mathrm{C}$ (Table 1$)$.

\section{Extrusion of filled nanocomposites:}

The 10, 15 and $20 \mathrm{wt} \%$ samples were selected to be scaled up in a $1.9 \mathrm{~L}$ jar for further testing that included extrusion. Upon termination of mixing, the melt viscosities of the samples were determined. As seen from Figure 7, the melt viscosity of the $10 \mathrm{wt} \%$ samples increased as a result of the scale up whereas the opposite was observed for 15 and $20 \mathrm{wt} \%$. It is not clear why with scaling up the melt viscosity decreases. No significant differences in $\mathrm{Tg}$ or HRSEM were observed between the initial and scaled up samples. 
The neat as well as the nanocomposite samples were extruded through a LME. The temperature of the mandrel was between 210 and $215{ }^{\circ} \mathrm{C}$ while the die temperature was set at $230{ }^{\circ} \mathrm{C}$. In case of the neat resin it was difficult to obtain continuous fibers even though the die temperature was raised to $300{ }^{\circ} \mathrm{C}$. This is due to the low melt viscosity of the resin. However, as seen from Figure 8, extrusion at temperatures up to $300{ }^{\circ} \mathrm{C}$ did not affect the melt viscosity of the resin indicating that no crosslinking was taking place. In case of $10 \mathrm{wt} \%$ samples, fibers of $\sim 1 \mathrm{~m}$ length were extruded at a uniform output rate. Figure 9 shows the extruded strands. In case of the 20 wt \% samples, difficulties were encountered during feeding and the rotor temperature rose to $245{ }^{\circ} \mathrm{C}$ due to frictional heat buildup. The extrusion of the $15 \mathrm{wt} \%$ sample was similar to the $10 \mathrm{wt} \%$ sample, but feeding was not always smooth and required occasional manual pressure. The resulting fibers were still very brittle as the resin matrix was not cured. One significant observation was an alignment of the nanotubes as a result of the extrusion. Figure 10 (a) is the HRSEM picture of the surface of the 10 wt \% extruded fiber and most of the tubes are aligned in the direction of fiber extrusion. The orientation of the tubes is more apparent at the end of the fibers as seen in Figure 10 (b). We observed that a majority of the MWNTs are unidirectionally aligned in the polymer matrix.

\section{PETI 330 and 10\% (wt/wt) MWNT: in situ and in solution}

MWNTs (10 wt \%) were added to PETI-330 by two different methods other than ball-milling. In the first method (i.e. in situ) the PETI oligomer was prepared from the monomers in solution in presence of the MWNTs. In the second method the tubes were added to a solution of PETI-330 in NMP. Both of these batches were characterized and compared with the dry mixing technique. As evident from Figure 11, the melt viscosity at $280{ }^{\circ} \mathrm{C}$ of the 
sample prepared by dissolving the polymer in solution was at least one order of magnitude higher than that prepared by ball milling. The higher viscosity has a negative effect on the processing as evident from the extrusion of the sample that failed to yield continuous strands like the ball-milled samples (Figure 12). Although the melt viscosity of the in situ samples was similar to that of the ball-milled sample, continuous strands were not obtained during extrusion.

The samples prepared in solution were also characterized by DSC and HRSEM. The Tgs of the samples were higher than those of the ball-milled samples (Table 2). A comparison of the HRSEM pictures (Figure 13) at a fixed voltage and magnification $(1.0 \mathrm{kV}$ and $5.0 \mathrm{k})$ show that the tubes seem to be more uniformly dispersed when added to the PETI in solution or prepared in situ.

\section{SUMMARY}

Typical methods for addition of CNTs to the polymer matrix involve melt mixing or the use of a suitable solvent. Although ball milling has been used recently to incorporate CNFs into the polymer matrix, there are no reports of mixing MWNTs into the polymer using the same technique. The fabrication of nanocomposites that contain high loadings ( $>3 \%$ by weight) of carbon nanotubes has been elusive but in this research incorporation of high loadings (up to $25 \mathrm{wt} \%$ ) of MWNTs into a polyimide matrix was possible without exceeding the maximum tolerable melt viscosity for processing (extrusion or injection molding) of the composites. Select samples were scaled up for processing and continuous strands of the nanocomposites were extruded. These strands showed significant alignment along the direction of extrusion. The next step in this research is to perform injection molding of select samples to produce plaques for testing the degree of MWNT dispersion, and thermal, electrical and mechanical properties. 


\section{Acknowledgement}

The authors would like to thank Dr. Peter Lillehei and Dr. Roy Crooks for their help with the HRSEM and HRTEM respectively and to Mr. Pert Razon for his help with the ARES. They would also like to thank Dr. P. M. Hergenrother and Dr. J. G. Smith for their valuable discussion. 


\section{List of figures:}

Figure 1: $\quad$ Complex melt viscosity of PETI-330 and various amounts of MWNT

Figure 2: $\quad$ HRSEM images of neat MWNTs $(a-b)$ and powder PETI-330/MWNT samples $(\mathrm{c}-\mathrm{f})$ obtained after ball milling

Figure 3: $\quad$ HRSEM images of PETI-330/MWNT samples obtained after the ARES

Figure 4: $\quad$ Images and data of neat MWNTs obtained from TEM

Figure 5: $\quad$ TEM images of PETI-330 + $15 \mathrm{wt} \%$ MWNTs after ball-milling

Figure 6: Raman spectra of (a) powder and (b) ARES samples of PETI-330/ MWNTs

Figure 7: $\quad$ Complex melt viscosity of scaled up samples

Figure 8: $\quad$ Melt viscosity of PETI-330 before and after extrusion

Figure 9: $\quad$ PETI-330/MWNT (10 wt \%) strands after extrusion

Figure 10: HRSEM images of PETI-330/ 10 wt \% MWNT samples obtained after extrusion

Figure 11: Melt viscosity of PETI-330/ 10 wt \% MWNT prepared by various methods

Figure 12: $\quad$ Extrusion of PETI-330/ $10 \mathrm{wt} \%$ MWNT prepared in solution

Figure 13: $\quad$ HRSEM of PETI-330/10 wt \% MWNT prepared by (a) ball-milling (b) in situ and (c) in solution

\section{Tables:}

Table 1: $\quad$ Glass transition temperatures (Tg) and temperature at $5 \% \mathrm{wt}$ loss

Table 2: $\quad$ Glass transition temperatures ( $\mathrm{Tg}$ ) of ball-milled, in situ and in solution samples 


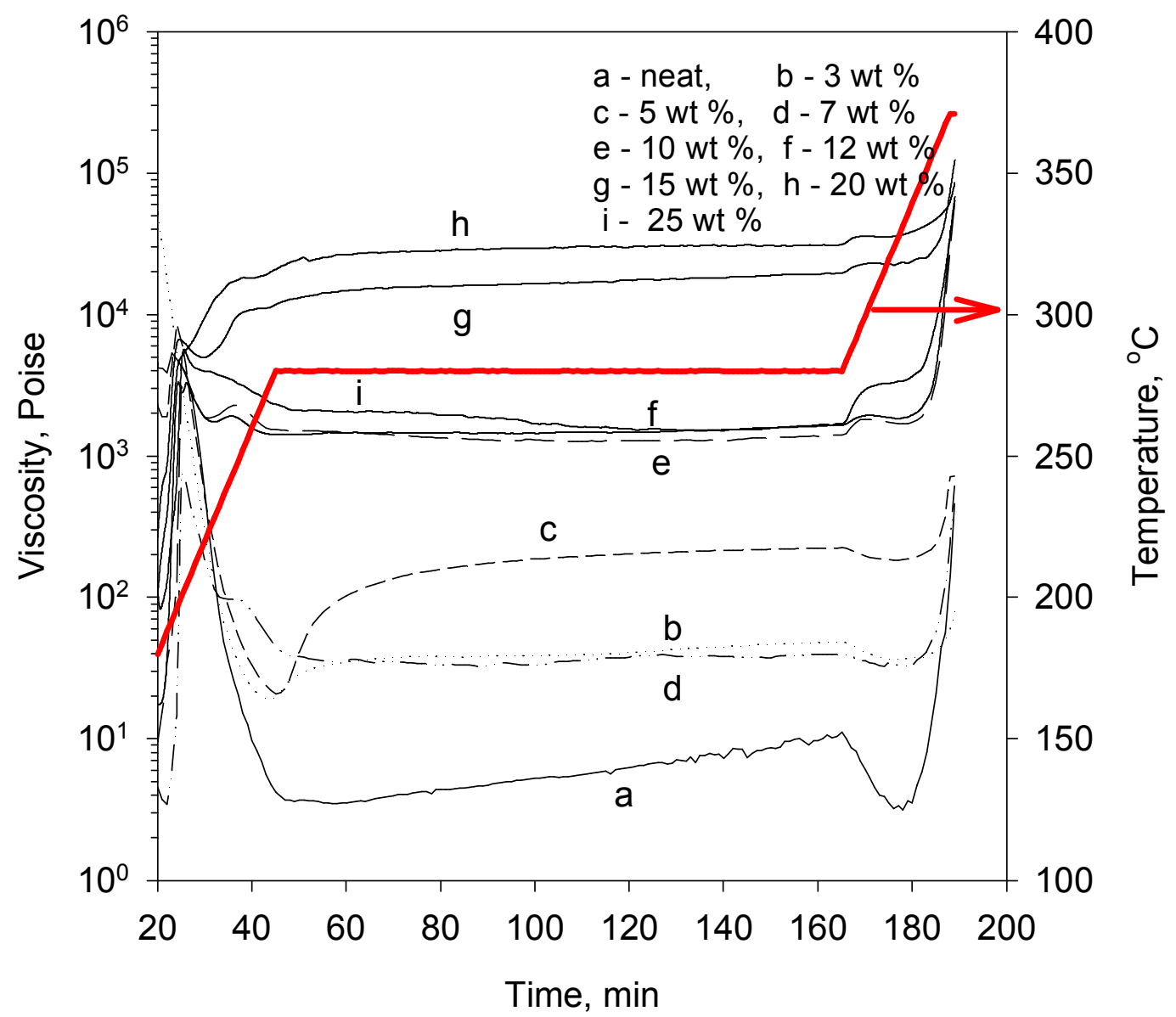

Figure 1: Complex melt viscosity of PETI-330 and various amounts of MWNT 


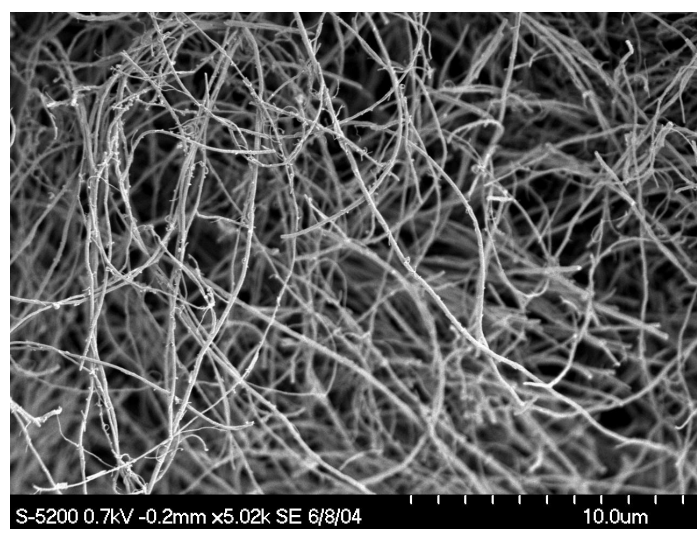

(a) Neat MWNTs

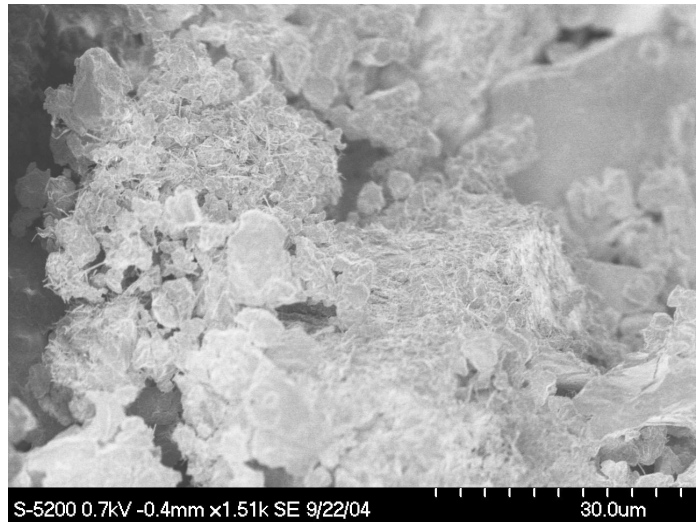

(c) PETI-330 + $10 \mathrm{wt} \% \mathrm{MWNT}$

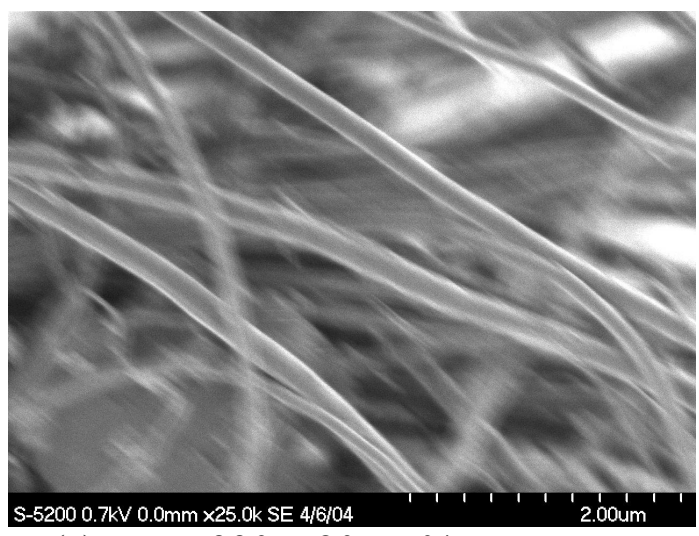

(e) PETI-330 + 20 wt \% MWNT

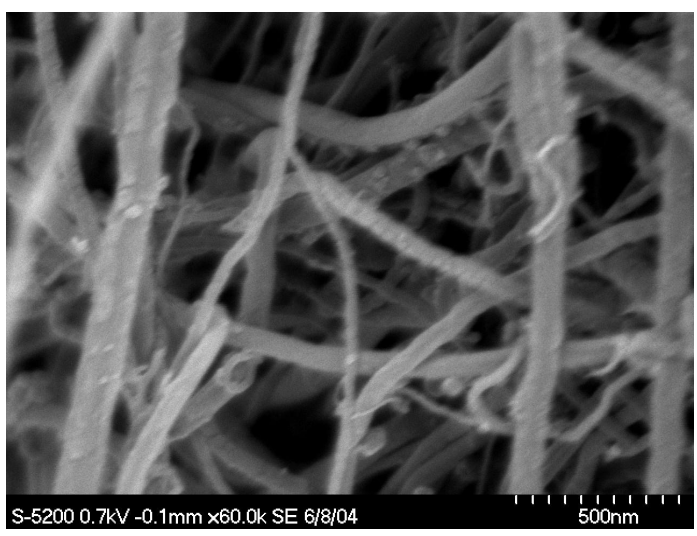

(b) Neat MWNTs

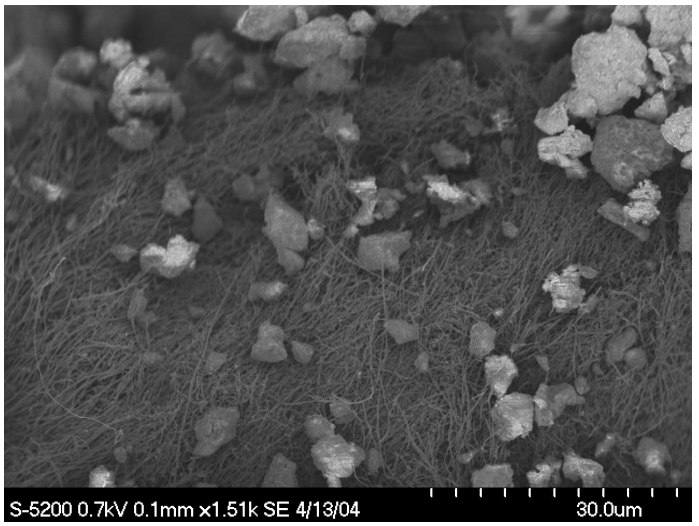

(d) PETI-330 + 25 wt \% MWNT

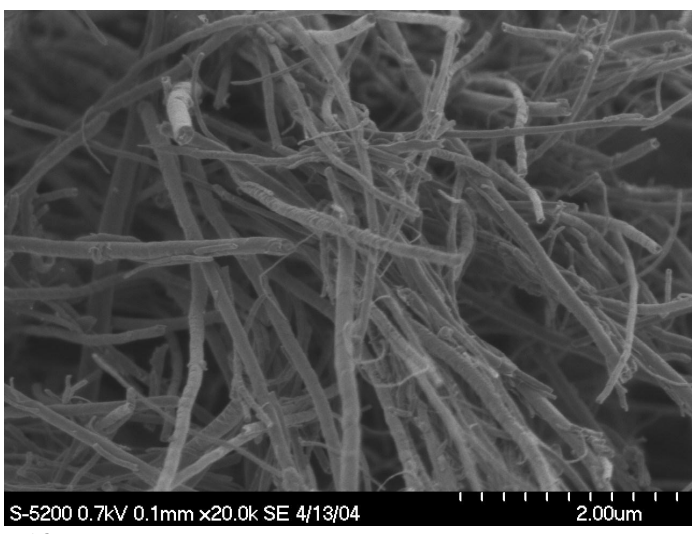

(f) PETI-330 + 25 wt \% MWNT

Figure 2: HRSEM images of neat MWNTs $(\mathrm{a}-\mathrm{b})$ and powder PETI-330/MWNT samples $(\mathrm{c}-\mathrm{f})$ obtained after ball milling 


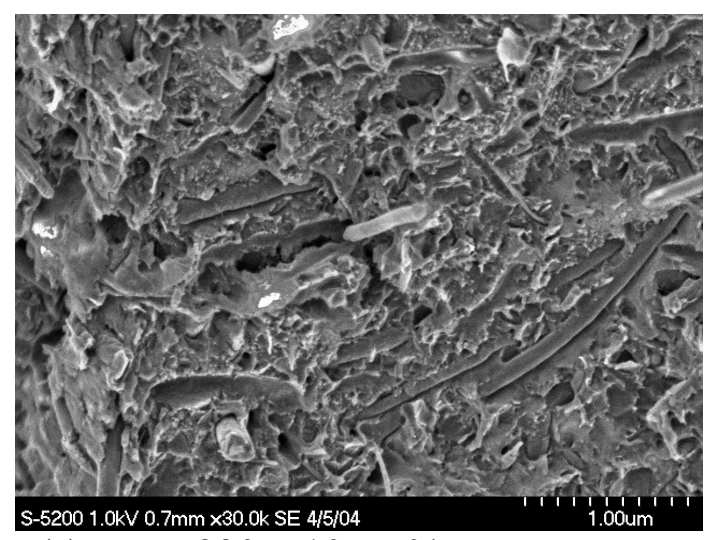

(a) PETI-330 + $10 \mathrm{wt} \%$ MWNT

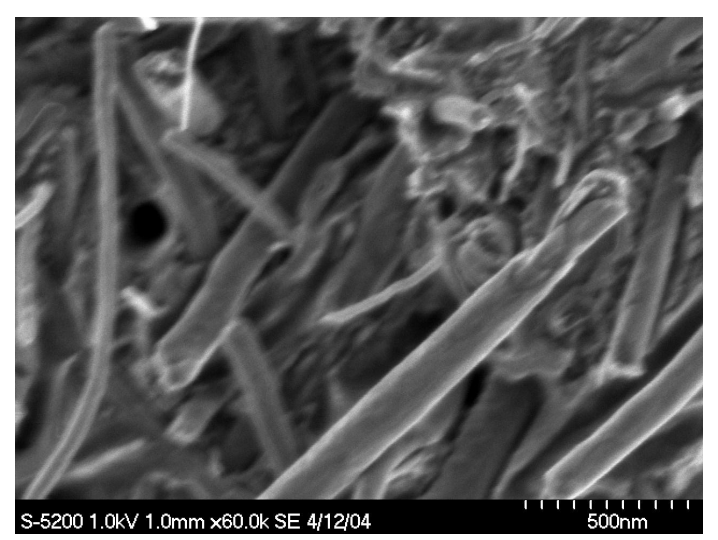

(c) PETI-330 + $20 \mathrm{wt} \%$ MWNT

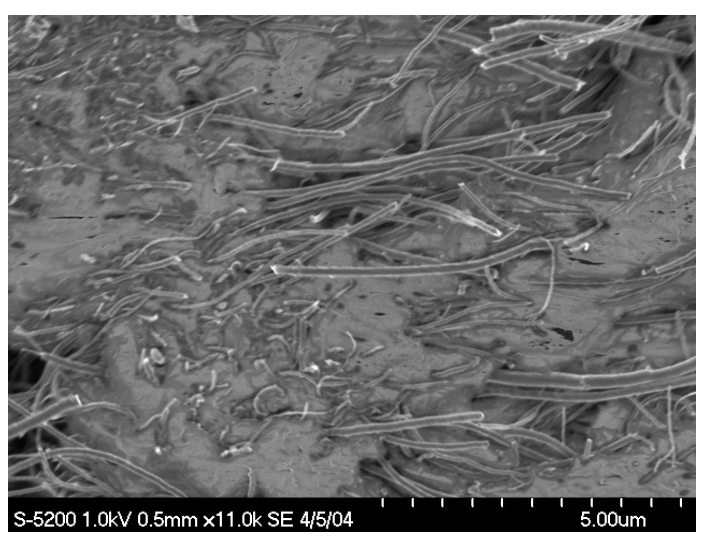

(b) PETI-330 + 15 wt \% MWNT

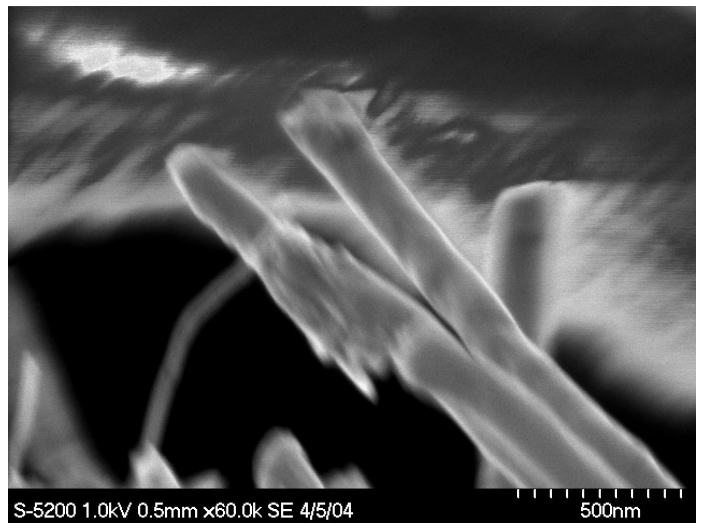

(d) PETI-330 + 15 wt \% MWNT

Figure 3: HRSEM images of PETI-330/MWNT samples obtained after the ARES 


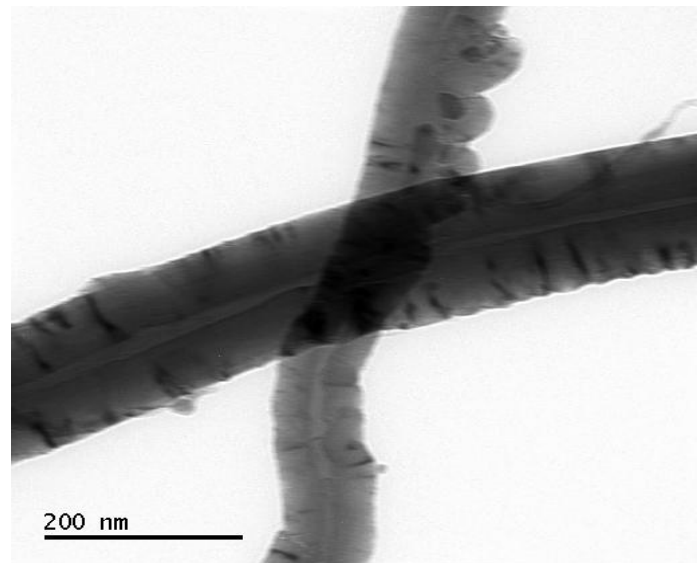

(a)

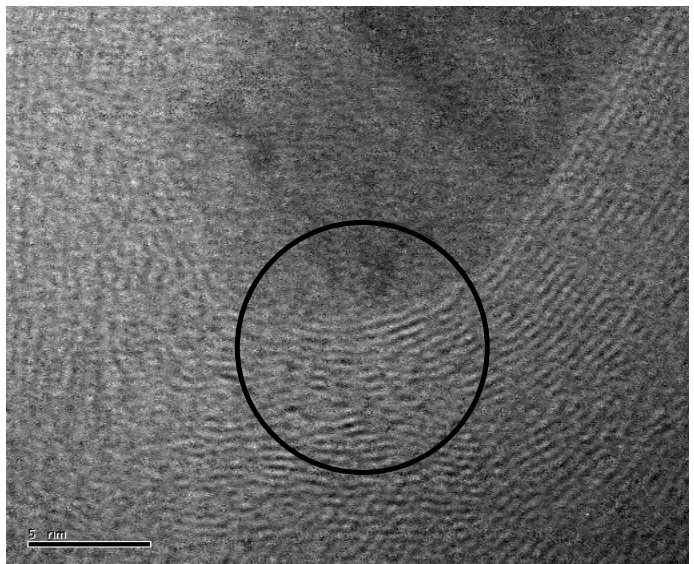

(b)

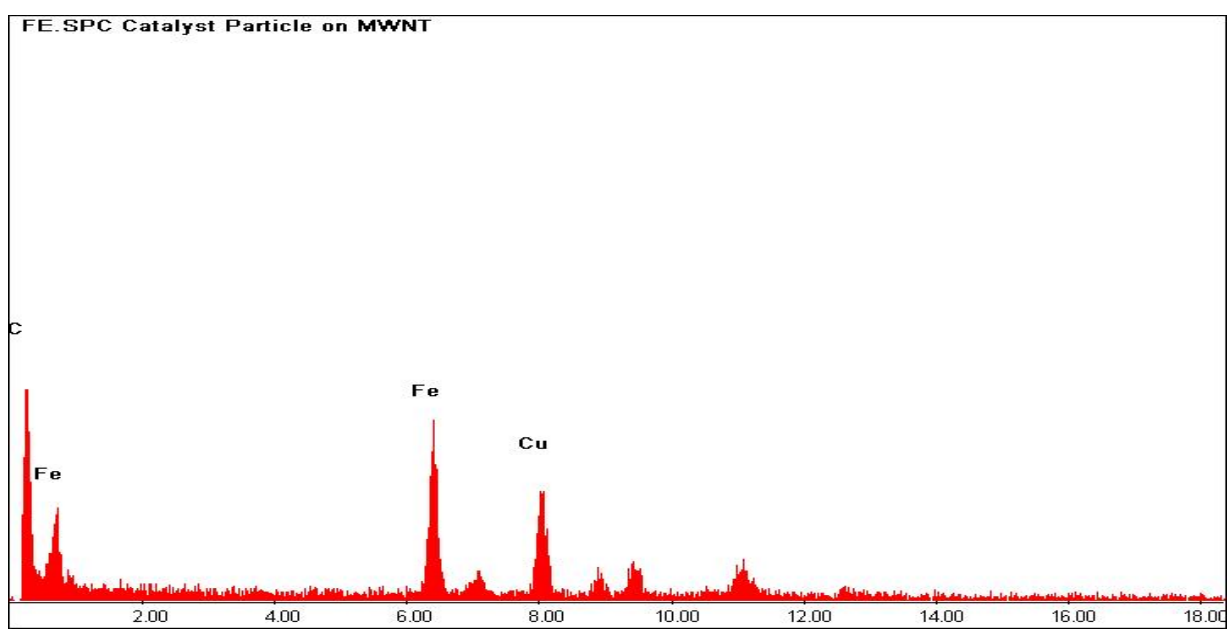

(c)

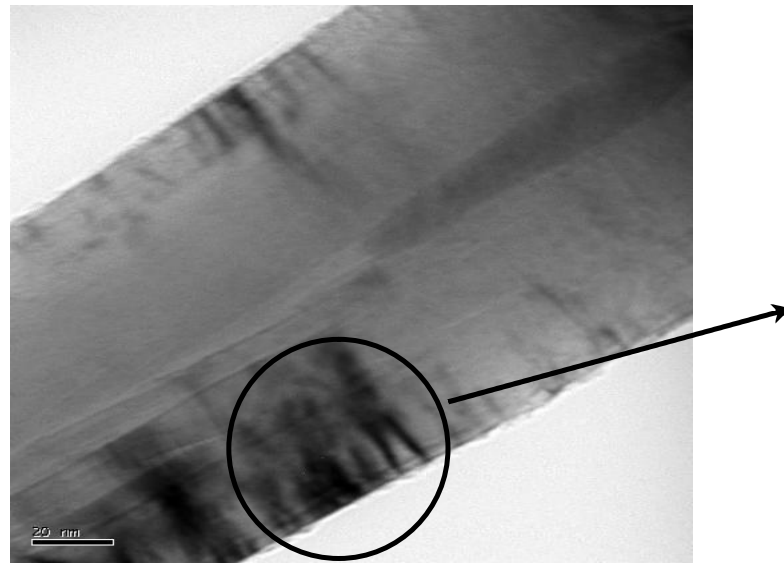

(d)

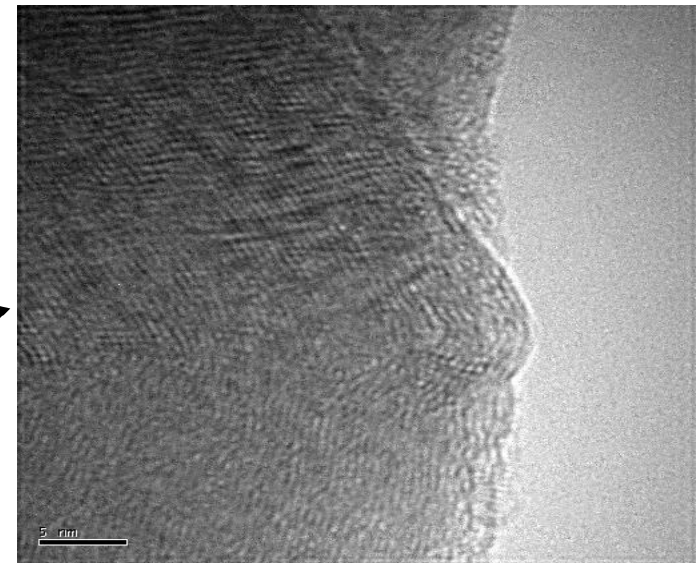

(e)

Figure 4: Images and data of neat MWNTs obtained from TEM 


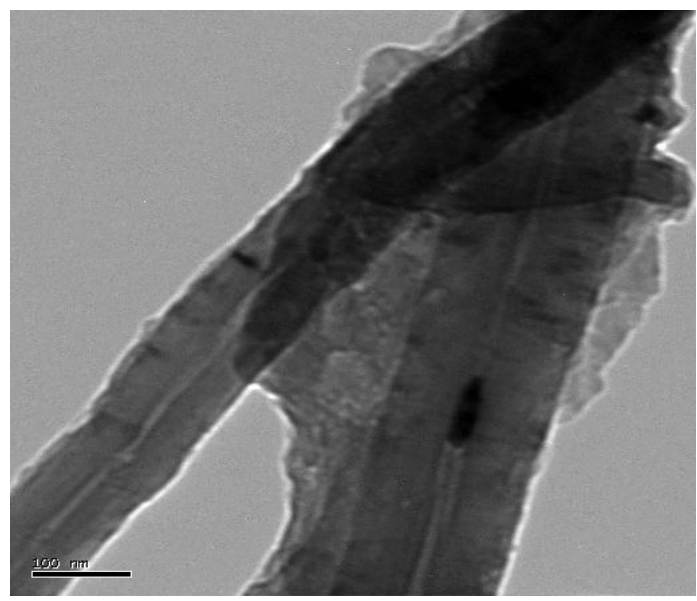

(a)

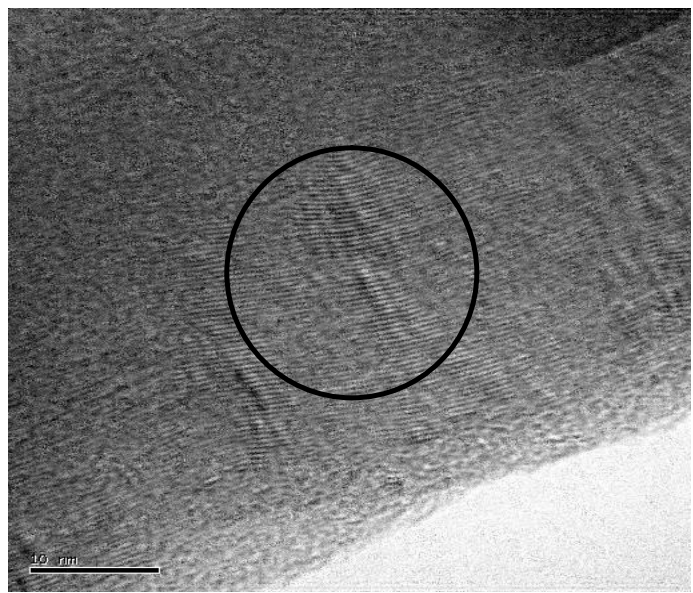

(c)

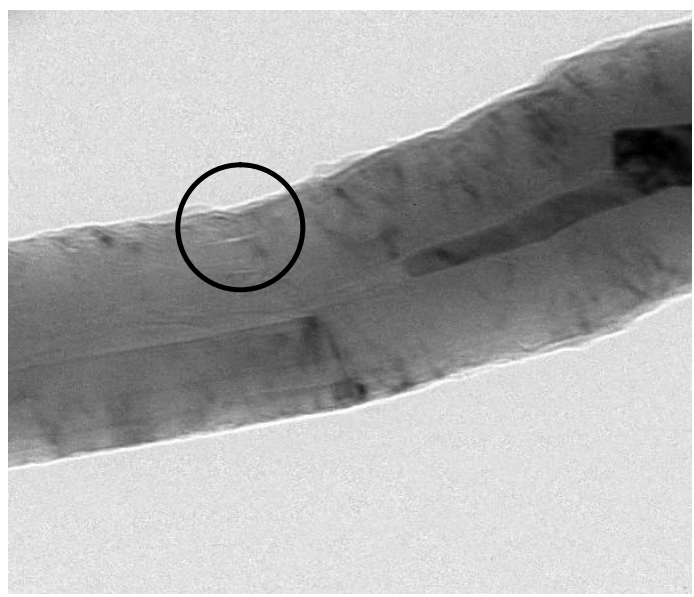

(b)

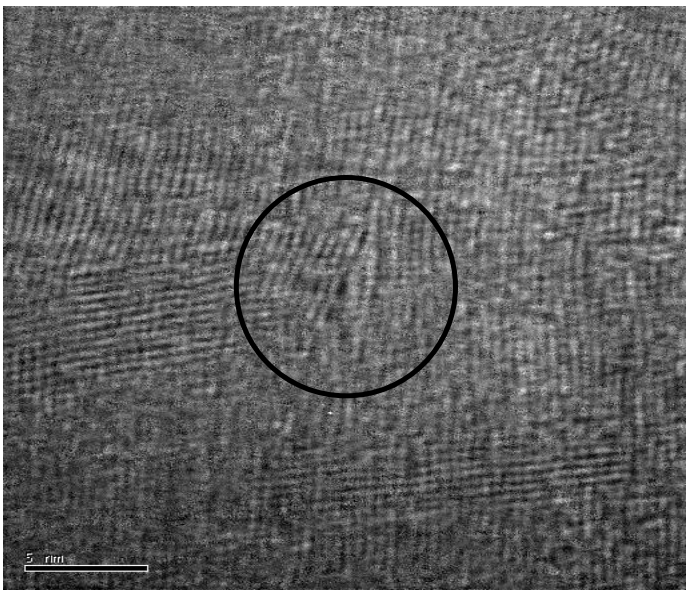

(d)

Figure 5: TEM images of PETI-330 + 15 wt \% MWNTs after ball-milling 
(a)

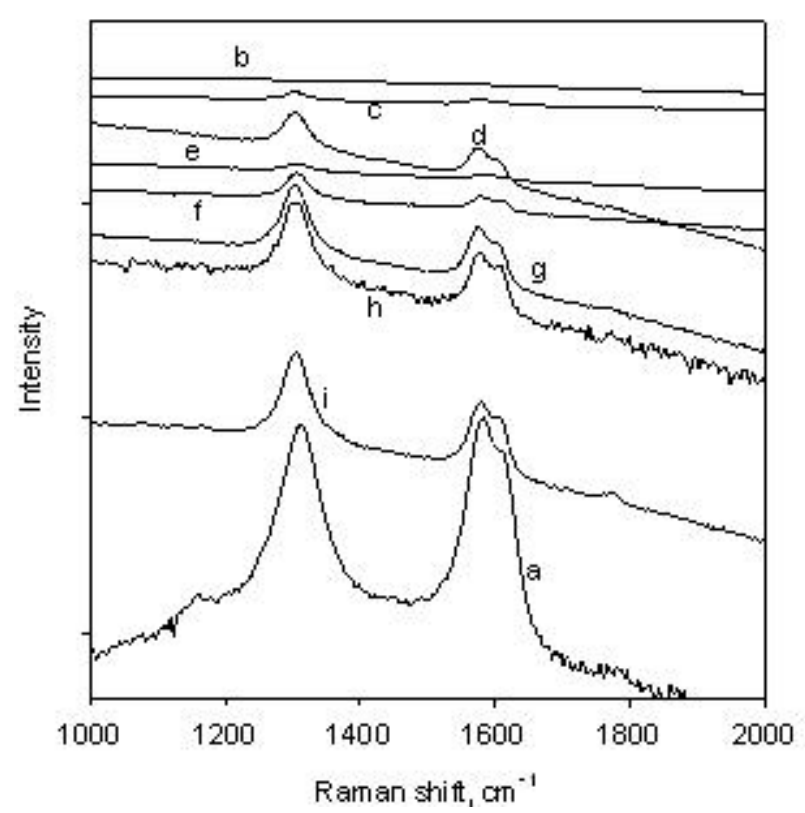

(b)

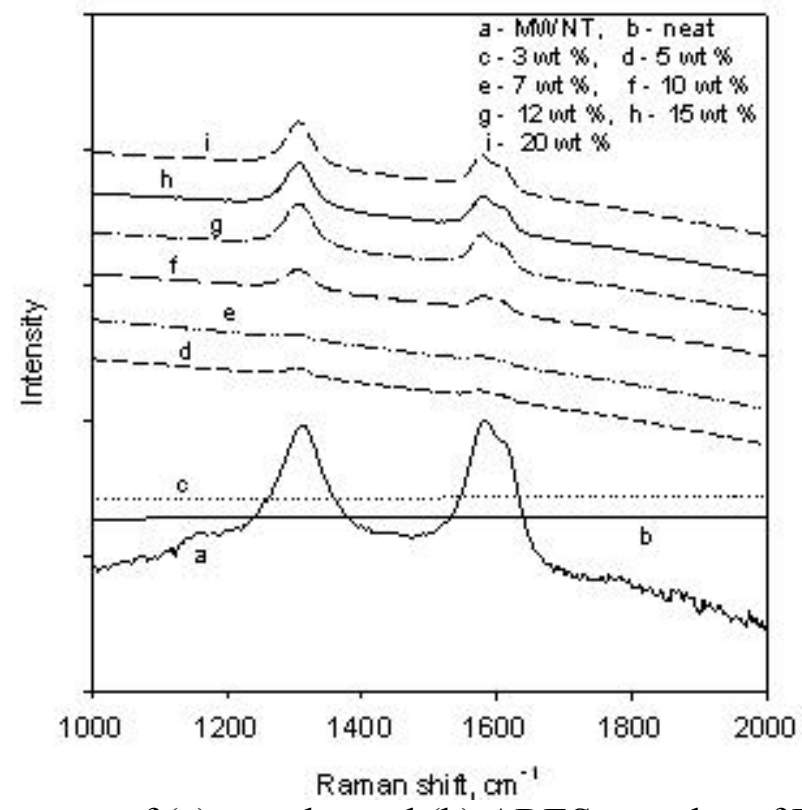

Figure 6: Raman spectra of (a) powder and (b) ARES samples of PETI-330/ MWNTs 


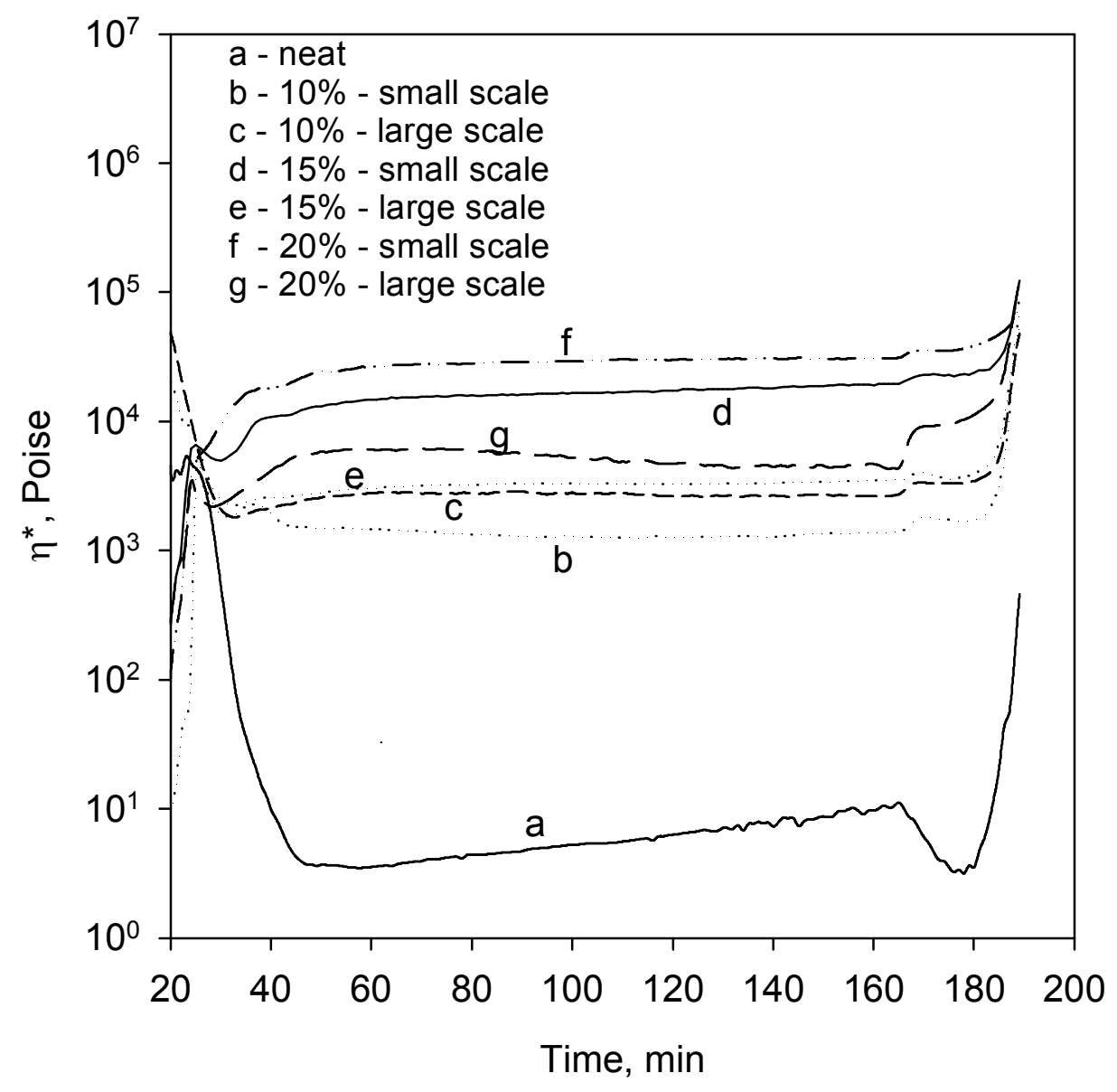

Figure 7: Complex melt viscosity of scaled up samples 


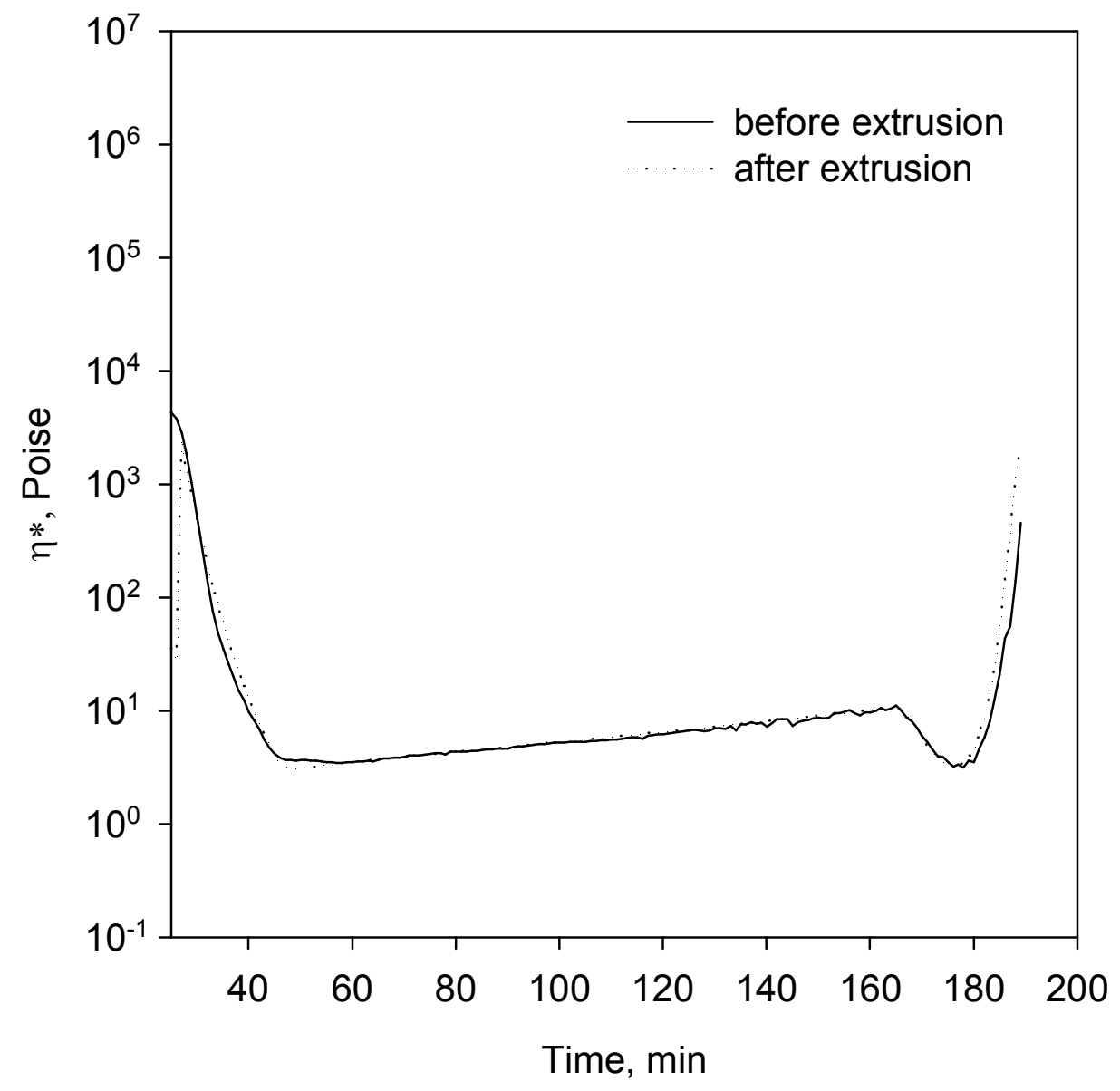

Figure 8: Melt viscosity of PETI-330 before and after extrusion 


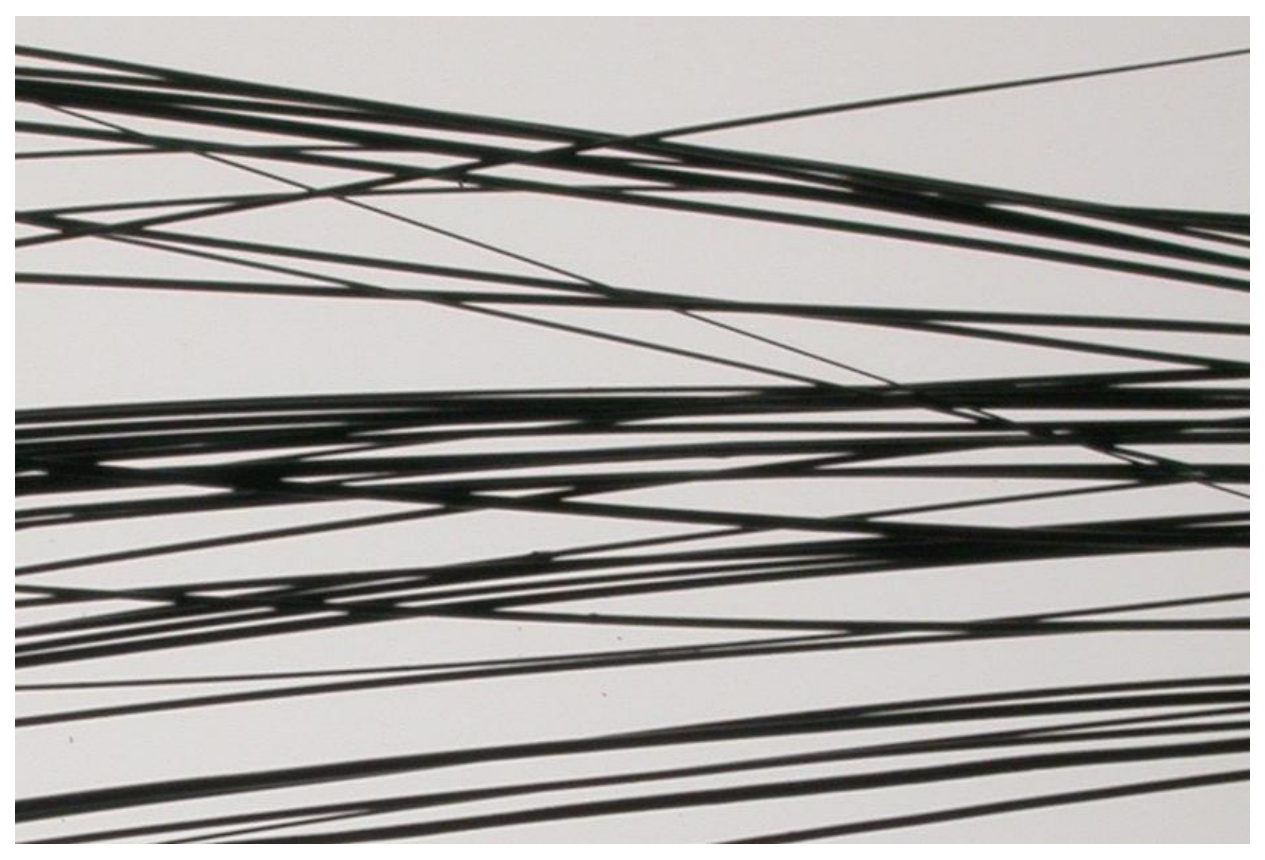

Figure 9: PETI-330/MWNT (10 wt \%) strands after extrusion 
(a)

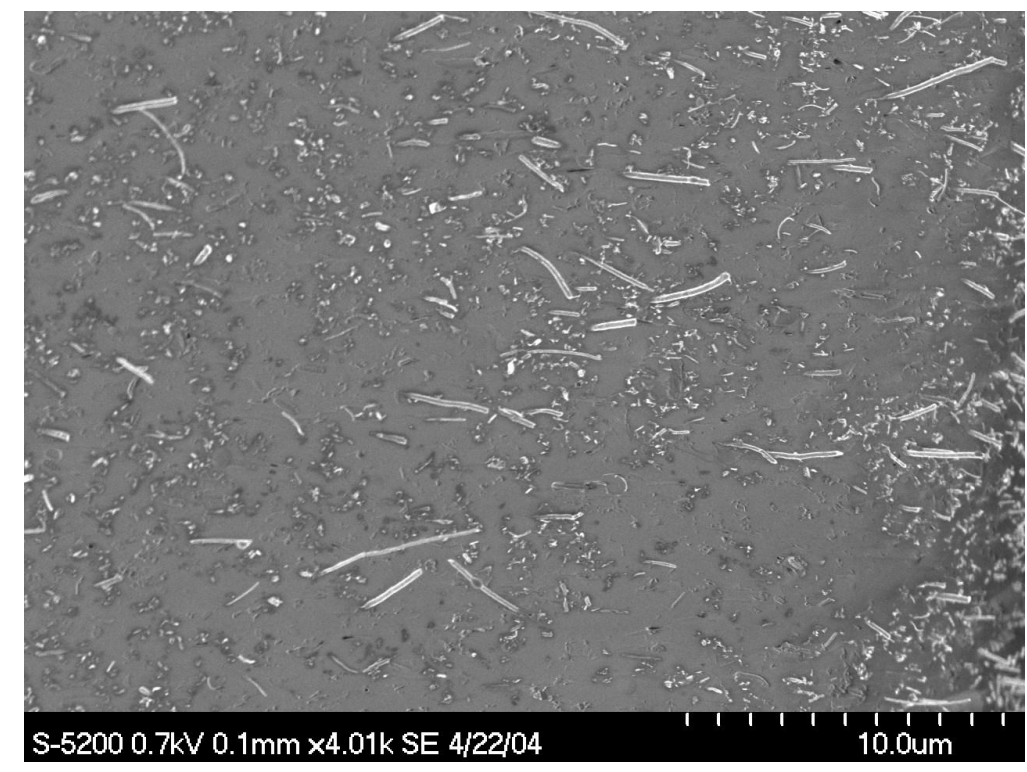

(b)

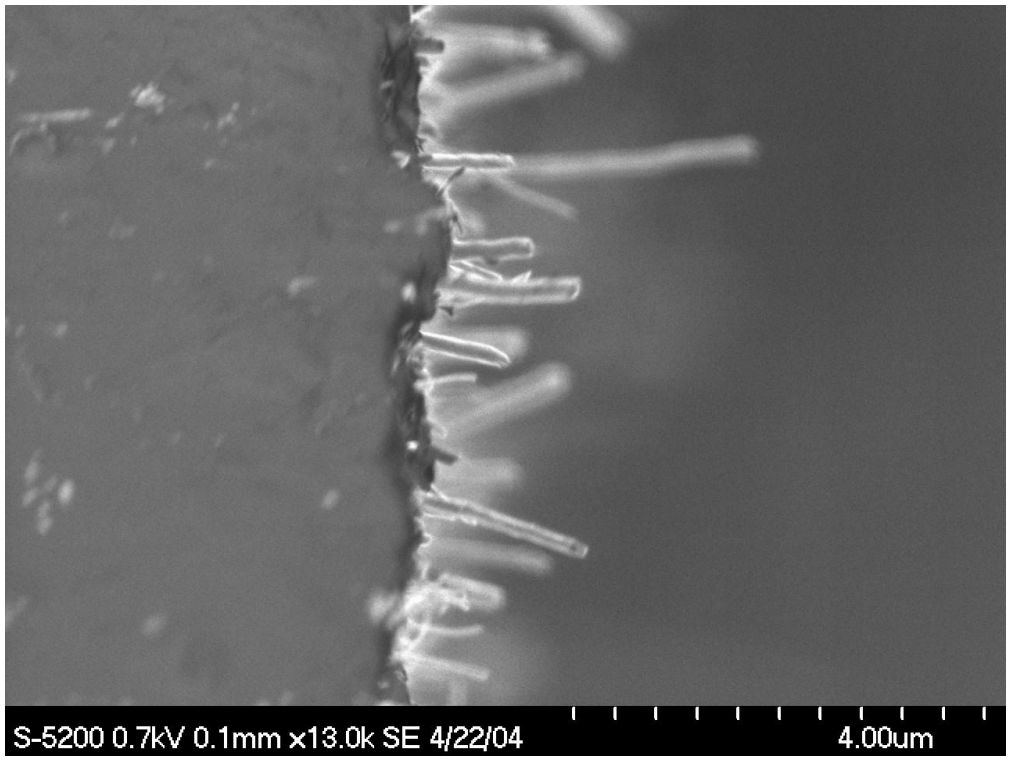

Figure 10: HRSEM images of PETI-330/ $10 \mathrm{wt} \%$ MWNT samples obtained after extrusion 


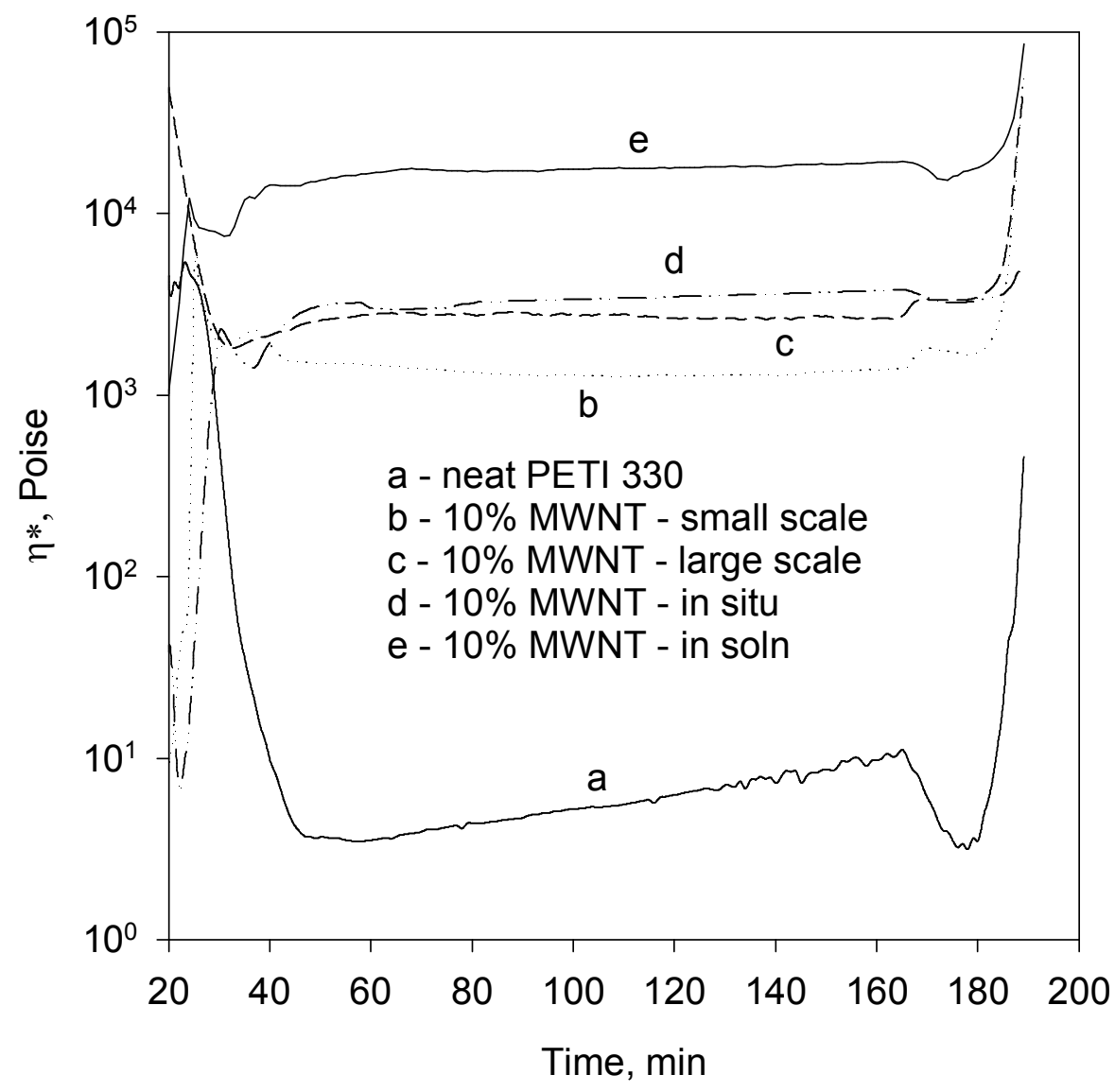

Figure 11: Melt viscosity of PETI-330/ $10 \mathrm{wt} \%$ MWNT prepared by various methods

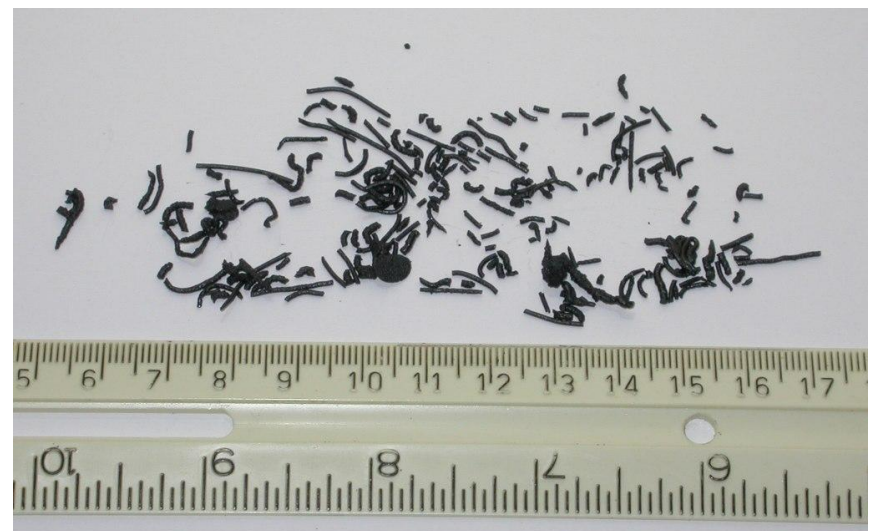

Figure 12: Extrusion of PETI-330/ $10 \mathrm{wt} \%$ MWNT prepared in solution 


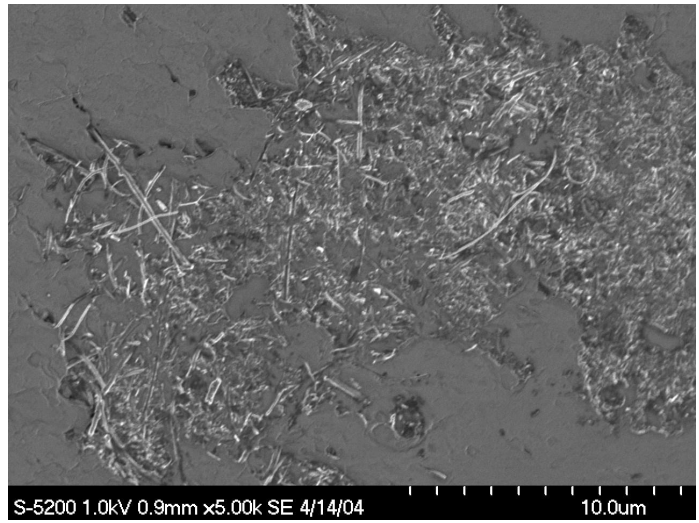

(a)

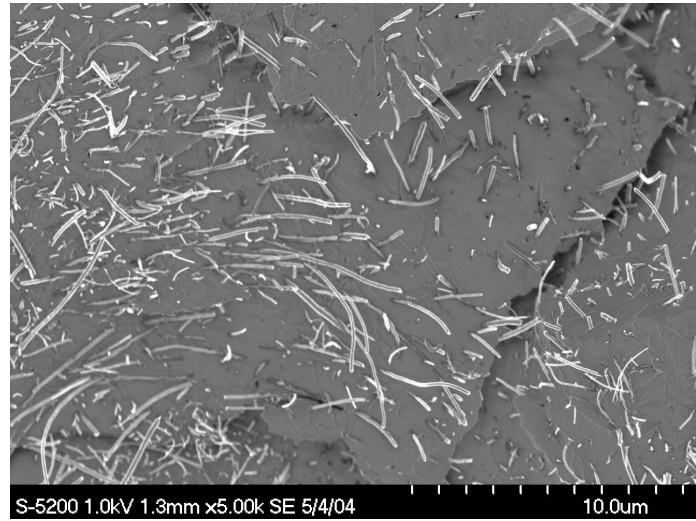

(b)

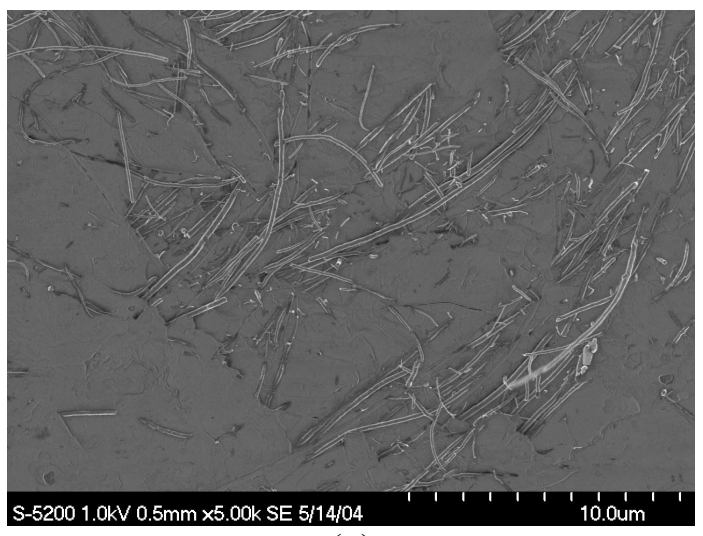

(c)

Figure 13: HRSEM of PETI-330/10 wt \% MWNT prepared by (a) ball-milling (b) in situ and (c) in solution 
Table 1: Glass transition temperatures $(\mathrm{Tg})$ and temperature at $5 \% \mathrm{wt}$ loss:

\begin{tabular}{|c|c|c|}
\hline Sample & $\mathrm{Tg},{ }^{\circ} \mathrm{C}$ & $\begin{array}{c}\text { Temperature at 5 \% wt loss, } \\
{ }^{\circ} \mathrm{C} \text { (in air) }\end{array}$ \\
\hline PETI-330-neat & 326 & 508 \\
\hline$+3 \mathrm{wt} \% \mathrm{MWNT}$ & 325 & 473 \\
\hline$+5 \mathrm{wt} \% \mathrm{MWNT}$ & 328 & 479 \\
\hline$+7 \mathrm{wt} \% \mathrm{MWNT}$ & 329 & 484 \\
\hline$+10 \mathrm{wt} \% \mathrm{MWNT}$ & 329 & 485 \\
\hline$+12 \mathrm{wt} \% \mathrm{MWNT}$ & 331 & 482 \\
\hline$+15 \mathrm{wt} \% \mathrm{MWNT}$ & 332 & 491 \\
\hline$+20 \mathrm{wt} \% \mathrm{MWNT}$ & 332 & 464 \\
\hline$+25 \mathrm{wt} \% \mathrm{MWNT}$ & 332 & 462 \\
\hline
\end{tabular}

Table 2: Glass transition temperatures (Tg) of ball-milled, in situ and in solution samples

\begin{tabular}{|c|c|}
\hline Sample & $\mathrm{Tg},{ }^{\circ} \mathrm{C}$ \\
\hline PETI-330 - neat & 326 \\
\hline+10 wt \% MWNT ( small scale) & 329 \\
+10 wt \% MWNT (scale up) & 331 \\
\hline+10 wt \% MWNT - in situ & 337 \\
\hline+10 wt \% MWNT - in solution & 334 \\
\hline
\end{tabular}




\section{References:}

1 Wilson D, Stenzenberger HD, Hergenrother PM. "Polyimides", Blackie and Sons Ltd., Glasgow, UK, 1990.

2 Hergenrother PM. High Performance Polymers 2003; 15(1): 3.

3 Connell JW, Smith JG Jr, Hergenrother PM, Rommel ML. Intl. SAMPE Tech. Conf. Series 1998; 30: 545.

4. Criss JM, Connell JW and Smith JG Jr. Intl. SAMPE Tech. Conf. Series 1998; 30: 341.

5. Criss JM, Arendt CP, Connell JW, Smith JG Jr, Hergenrother PM. SAMPE J 2000; 36(3): 32.

6. Smith JG Jr, Connell JW, Hergenrother PM, Criss JM. Soc. Adv. Mat. Proc. Eng. Ser. 2001; 46: 510.

7. Smith, JG Jr, Connell JW, Hergenrother PM, Criss JM. J. Comp. Matls 2002; 36 (19): 2255.

8. Criss JM, Koon RW, Hergenrother PM, Connell JW, Smith JG Jr. Intl. SAMPE Tech. Conf. Series 2001; 33: 1009.

9. Smith JG Jr., Connell JW, Hergenrother PM, Yokota R, Criss JM. Soc. Adv. Mat. Proc. Eng. Ser. 2002; 47: 316.

10. Smith JG Jr., Connell JW, Hergenrother PM, Ford LA, Criss JM. Macromol. Symp. 2003; 199: 401.

11. Connell JW, Smith JG Jr., Hergenrother PM. U.S. Patent 6,359,107 B1 to NASA 2002.

12. Criss JM, Meador MA, Chuang KC, Connell JW, Smith JG Jr., Hergenrother PM, Mintz EA. Soc. Adv. Mat. Proc. Eng. Ser. 2003; 48: 1063.

13. Connell JW, Smith JG Jr., Hergenrother PM, Criss JM. Intl. SAMPE Tech. Conf. Series 2003; 35.

14 Connell JW, Smith JG Jr., Hergenrother PM, Criss JM, Soc. Adv. Mat. Proc. Eng. Ser. 2003; 48: 1076 
15 Watson KA, Smith JG Jr., Connell JW. Soc.Adv.Mat.Proc.Eng Ser. 2003; 48: 1145 .

16 Park C, Ounaies Z, Watson KA, Crooks RE, Smith JG Jr., Lowther SE, Connell JW, Siochi EJ, Harrison JS, St. Clair TL. Chem. Phys. Lett.2002; 364: 303.

17 Smith JG Jr., Connell JW, Hergenrother PM, 46'th International SAMPE Symposium and Exhibition 2001; 46: 510.

18 Haggenmueller R, Gommans HH, Rinzler AG, Fischer JE, Winey KI. Chem Phys Lett 2000; 330: 219.

19 Jin Z, Pramoda KP, Xu G, Goh SH. Chem Phys Lett 2001; 337: 43.

20 Potschke P, Fornes TD, Paul DR. Polymer 2002; 43: 3247.

21 Thostenson ET, Chou T. J. Phys. D: Appl. Phys. 2002; 35: L77.

22 Siochi EJ, Working DC, Park C, Lillehei PT, Rouse JH, Topping CT, Bhattacharya AR, Kumar S. Composites: Part B 2004; 35: 439.

23 Konya Z, Zhu J, Niesz K, Mehn D, Kiricsi I. Carbon 2004; 42: 2001.

24 Kim YA, Hayashi T, Fukai Y, Endo M, Yanagisawa T, Dresselhaus M. Chem. Phys. Lett. 2002; 355(3-4): 279.

25 Li YB, Wei BQ, Liang J, Yu Q, Wu DH. Carbon 1991; 37: 493.

26 Awasthi K, Kamalakaran R, Singh AK, Srivastava ON. Int J Hydrogen Energy 2002; 27: 425.

27 Huang JY, Yasuda H, Mori H. Chem. Phys. Lett. 1999; 303(1-2): 130

28 Pierard N, Fonseca A, Konya Z, Willems I, van Tendeloo G. Nagy JB, Chem. Phys. Lett. 2001; 335 (1-2): 1.

29 Pierard N, Fonseca A, Colomer JF, Bossuot C, Benoit JM, van Tendeloo G, Nagy JB. Carbon 2004; 42: 1691.

30 Kumar S, Uchida T, Dang T, Zhang X, Park Y. Soc. Adv. Mat.Proc. Eng. Ser. 2004; 49. 
31 Andrews R, Jacques D, Minot M, Rantell T. Macromol. Mater. Eng. 2002; 287: 395.

32 Potschke P, Bhattacharya AR, Janke A. Carbon 2004; 42: 965.

33 Ogasawara T, Ishida Y, Ishikawa T, Yokota R. Composites Part A 2004; 35: 67.

34 Chhowalla M, Teo KBK, Ducati C, Rupesinghe NL, Amaratunga GAJ, Ferrari AC, Roy D, Robertson J, Milne WI. J. Appl. Phys. 2001; 90(10): 5308.

35 Stephan C, Nguyen TP, Lahr B, Blau W, Lefrant S, Chauvet O. J. Mater. Res. 2002; 17(2): 396. 